原著

\title{
重症くも膜下出血患者の治療戦略とその転帰
}

\author{
木嶋 教行 ${ }^{1}$, 中川 智義 ${ }^{2}$, 三浦 慎平 ${ }^{3}$, 中川 僚太 ${ }^{1}$, 舘 哲郎 ${ }^{1}$ \\ 沖田 典子 ${ }^{1}$, 金村 米博 $^{1}$, 中島 伸 ${ }^{1}$, 藤中 俊之 ${ }^{1}$
}

\section{Therapeutic Strategies for Poor-grade Subarachnoid Hemorrhage Patients and Clinical Outcomes}

\author{
Noriyuki KıJIMa, M.D., Ph.D. ${ }^{1}$, Tomoyoshi Nakagawa, M.D. ${ }^{2}$, Shimpei MiuRA, M.D. ${ }^{3}$, \\ Ryota Nakagawa, M.D. ${ }^{1}$, Tetsuro Tachi, M.D. ${ }^{1}$, Yoshiko Okita, M.D., Ph.D. ${ }^{1}$, \\ Yonehiro Kanemura, M.D., Ph.D. ${ }^{1}$, Shin Naka.JMa, M.D., Ph.D. ${ }^{1}$, and \\ Toshiyuki FuJINAKA, M.D., Ph.D. ${ }^{1}$ \\ ${ }^{1}$ Department of Neurosurgery, Osaka National Hospital, National Hospital Organization, Osaka, \\ ${ }^{2}$ Department of Neurosurgery, Osaka University, Graduate School of Medicine, Suita, and \\ ${ }^{3}$ Department of Neurosurgery, Otemae Hospital, Osaka, Japan
}

Summary: Patients with poor-grade subarachnoid hemorrhage have a very poor prognosis, especially those with cardiopulmonary arrest and/or bilateral dilated pupils. Therapeutic indications for patients with poor-grade subarachnoid hemorrhage vary depending on the institution; however, we perform clipping or coil embolization in these patients with very poor-grade subarachnoid hemorrhage if their vital signs are stable at the time of admission. In this study, we summarize the outcomes of 31 patients with poor-grade subarachnoid hemorrhage seen between January 2015 and April 2017. Among the 31 patients, 13 patients had cardiopulmonary arrest at the time of admission and/or prehospital, and 15 patients had bilateral dilated pupils. Among these 13 patients with cardiopulmonary arrest, seven patients underwent clipping or coil embolization because their vital signs could be stabilized. The functional outcomes of these seven patients were very poor: mRS 1 (1 patient), mRS 4 (1 patient), and mRS 5 (5 patients); however, all of these patients survived 30 days after the subarachnoid hemorrhage onset. Meanwhile, the other nine patients with unstable vital signs and who could therefore not undergo clipping or coil embolization died within 30 days after the subarachnoid hemorrhage onset.

In conclusion, although the functional outcomes of patients with poor grade subarachnoid hemorrhage and cardiopulmonary arrest were very poor, a minority of these patients had good functional outcomes.

\section{Key words:}

- subarachnoid hemorrhage

- cardio-pulmonary arrest

- outcome

- poor grade

Surg Cereb Stroke

(Jpn) 49: 98-102, 2021

${ }^{1}$ 国立病院機構大阪医療センター 脳神経外科, ${ }^{2}$ 大阪大学大学院医学系研究科 脳神経外科, ${ }^{3}$ 大手前病院 脳神経外科 (受稿日 2018. 6. 22) （脱稿日 2019. 5. 29)〔連絡先：干 540-0006 大阪府大阪市中央区法円坂 2-1-14 国立病院機構大阪医療センター 脳神経外科 木嶋教行〕 [Address correspondence: Noriyuki Kijima, M.D., Ph.D., Department of Neurosurgery, Osaka National Hospital, National Hospital Organization, 2-1-14 Hoenzaka, Chuo-ku, Osaka, Osaka 540-0006, Japan] 
はじめに

重症くも膜下出血 (重症 SAH) は非常に予後が不良な病 態である。重症 SAH 患者の治療適応については各施設で 差があると思われるが，当院では発症時や搬送中 (以下,

入院前)に心肺停止 (cardiopulmonary arrest：CPA)をき たしたり，また両側瞳孔散大を呈するような最重症例で あっても，蘇生に速やかに成功しかつカテコラミンの投与 なしでバイタルサインが維持されているという条件下では 急性期に積極的な再出血予防治療を行っている(Fig. 1). このような方針で治療を行った当院での重症 SAH の治療 戦略とその治療成績につき報告する。

\section{方法}

2015 年 1 月から 2017 年 4 月までに経験した 54 例の $\mathrm{SAH}$ 症例を対象に解析した。 これらの症例に関して, 来 院時の重症度, CPA もしくは両側瞳孔散大の有無, 動脈 瘤の場所, さらには治療内容と 30 日以内の死亡率および 最終転帰につき解析した。統計手法としてはJMP $(\mathrm{SAS}$ Institute, Japan)を用いて $\mathrm{t}$ 検定を行い, $\mathrm{p}<0.05$ を有意差
ありとした．治療法としてはコイル塞栓術を第一選択とし ているが, 血腫形成型の SAH で頭蓋内圧コントロールの ために血腫の除去が必要と考えた症例についてはクリッピ ング術を行っている.

結果

当該期間内に経験した 54 例の SAH の搬送時の Grade （WFNS）は, Grade I 4 例，II 9 例， III 4 例，IV 6 例，V 31 例で, 重症くも膜下出血(WFNS GradeV) が多い傾向に あった (Table 1).さらに, 入院前にCPA を呈した例は 13 例，両側瞳孔散大は 15 例に認めた (Table 2). CPA を 呈した 13 例は，1例を除き，すべて両側瞳孔散大を呈し ていた。一方, CPAにはいたらないものの両側瞳孔散大 を呈したものは 3 例認めた. 入院前に CPA もしくは両側 瞳孔散大をきたした症例の動脈瘤の場所は, 中大脳動脈 4 例, 内澒動脈 4 例, 前交通動脈 3 例, 椎骨脳底動脈 4 例, 評価不可能であったものが 1 例であった.

一方，入院前に CPA をきたした 13 例においては，1 例 で心拍再開が得られなかったものの, 残りの 12 例は蘇生 が可能であった。この 12 例での CPA を呈してから蘇生

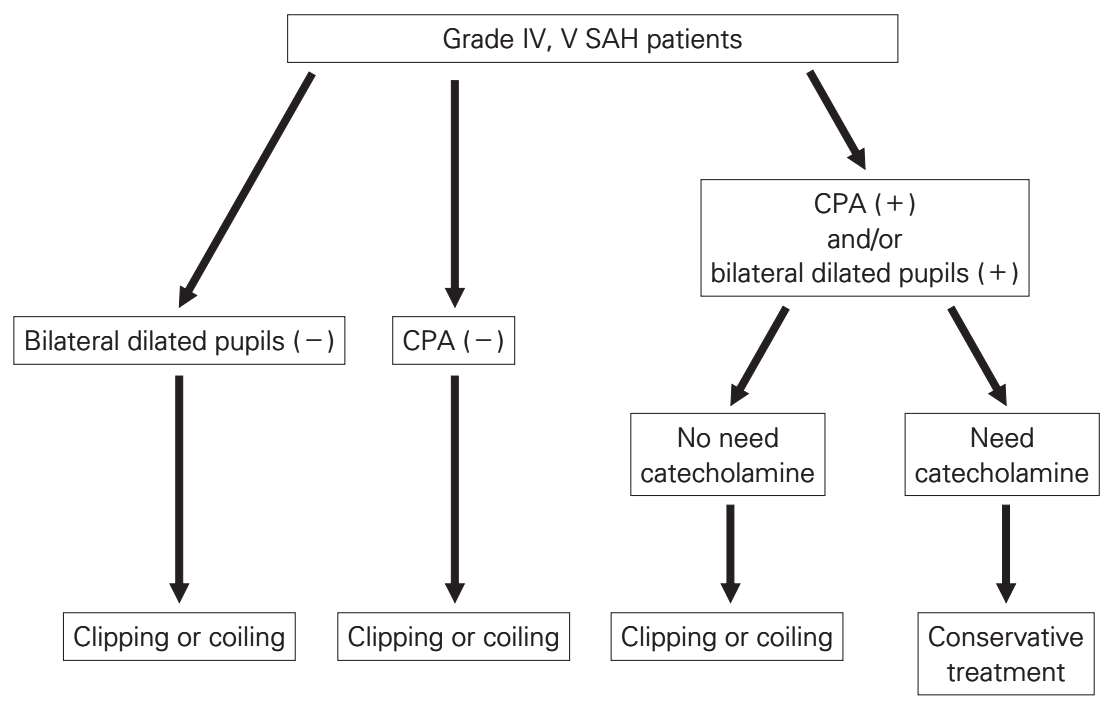

Fig. 1 Therapeutic strategy for poor-grade subarachnoid hemorrhage (SAH) patients at Osaka National Hospital.

Table 1 WFNS grade of 54 SAH patients

\begin{tabular}{cc}
\hline WFNS grade & No. of cases $(\%)$ \\
\hline I & $4(7.4 \%)$ \\
II & $9(16.7 \%)$ \\
III & $4(7.4 \%)$ \\
IV & $6(11.1 \%)$ \\
V & $31(57.4 \%)$ \\
\hline
\end{tabular}

Table 2 Characteristics of 31 poor-grade SAH patients

\begin{tabular}{cc}
\hline CPA/Bil. dilated pupils & No. of cases $(\%)$ \\
\hline Both & $12(38.7 \%)$ \\
CPA only & $1(3.2 \%)$ \\
Bil. dilated pupils only & $3(9.7 \%)$ \\
Neither & $15(48.4 \%)$ \\
\hline
\end{tabular}


Table 3 Characteristics of 16 poor-grade SAH patients with CPA and/or bilateral dilated pupils

\begin{tabular}{ccc}
\hline & & No. of cases (\%) \\
\hline WFNS Grade & I & $0(0 \%)$ \\
II & $0(0 \%)$ \\
IV & $0(0 \%)$ \\
Treatment & V & $0(0 \%)$ \\
& Clipping & $16(100 \%)$ \\
& Coil embolization & $3(18.8 \%)$ \\
& Conservative & $4(25.0 \%)$ \\
& treatment & $9(56.3 \%)$ \\
\hline
\end{tabular}

までの時間は 1-40 分(平均 21.75 分)であった。

入院前にCPA もしくは両側曈孔散大をきたしたものの バイタルサインが安定していた 7 例は, 再出血予防の治療 (クリッピング術 3 例, コイル塞栓術 4 例)を行った. これ ら 7 症例では 30 日以内の死亡例はなく, 最終転帰は modified Rankin Scale (mRS) 1 が 1 例, mRS 4 が 1 例, mRS 5 が 5 例という結果であった(Table 3, Fig. 2)。この 7 症例 のうち 5 例は入院前に $\mathrm{CPA}$ をきたした症例で, 残り 2 例 は CPA を呈していなかったが両側曈孔散大の状態で搬送 された症例であった。

一方, 入院前に CPA で蘇生が可能であったもののバイ タルサインが不安定で積極的な再出血予防治療を行うこと ができなかった症例を 9 例経験したが, 全例急性期に死亡 した(Fig. 2).

また，入院前にCPA を呈したものの, バイタルサイン が安定していたため治療を施行した 7 例とバイタルサイン が不安定なため治療を施行しなかった 9 例との比較では, CPA を呈してから蘇生までの平均時間は前者で 15.8 分, 後者で 26 分と, 有意差は認めなかったものの前者でやや 短い傾向があった $(\mathrm{p}=0.112)$.

\section{症例}

47 歳, 女性. 仕事中に突然の頭痛と意識障害を主訴に 当院へ救急搬送された。救急車内で 10 分間の CPA を認 め, 搬送時心拍は再開していたものの自発呼吸は停止, 意 識レベルはJapan Coma Scale(JCS) 300, 両側瞳孔は散大 している状態であった. CT 上は Fisher Group 3 の SAH を認め, digital subtraction angiography(DSA)上は右椎 骨動脈に解離性動脈瘤を認めた. カテコラミンなしで血圧 が安定した状況であったため, Day 0 に血管内治療による 母血管閉塞を施行した. 術後は経過は良好で, 脳血管攣縮 による神経学的悪化もなく, 最終的にDay 43 に mRS 1 にて自宅退院となった(Fig. 3).

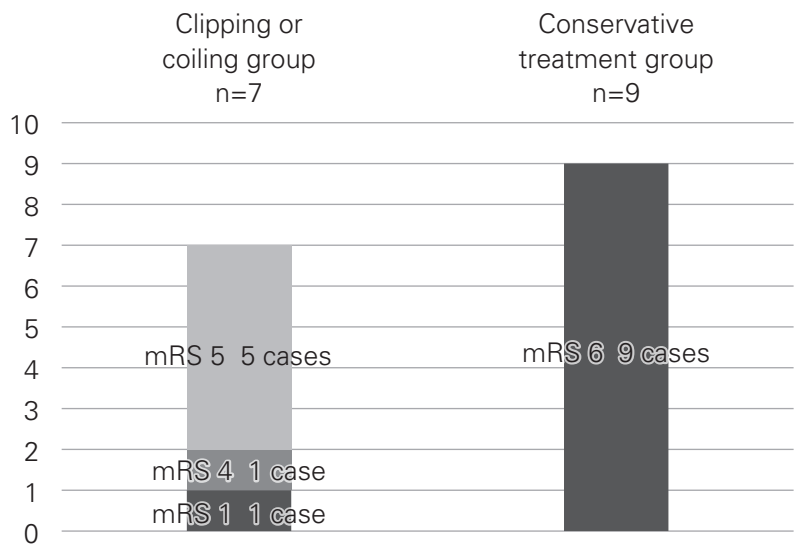

Fig. 2 Outcomes of 16 poor-grade subarachnoid hemorrhage (SAH) patients with CPA and/or bilateral dilated pupils. In the clipping or coiling group, one case was modified Rankin Scale (mRS) 1, one case was mRS 4, and five cases were mRS 5 at discharge.

In the conservative treatment group, all nine patients were mRS 6 at discharge.

\section{考察}

重症 SAH のうち CPA や両側曈孔散大を呈するような 症例は最重症であり, 生命予後, 機能予後ともに不良のた め, 治療適応となりにくいのが現状である.

これまでの CPA を伴う SAH に関する報告では, CPA を伴う SAH の頻度は全 SAH中 3-11\%と報告されてい

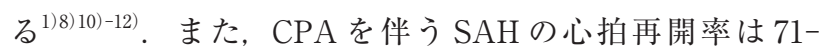
$100 \%$ と報告されており, 心原性の CPA と比較して蘇生 成功率は高いと報告されている ${ }^{1) 5)}$ 。さらに, CPA から蘇 生までの時間は1-26 分までと報告されている ${ }^{49)}$ 10).

$\mathrm{CPA}$ からの蘇生率は比較的高い反面, 最終的な治療成 績は不良であることが多く, 退院時の生存率が 0-55\%と 種々の報告がなされている(1)57)10)。これらをまとめた review では, 82 例の CPA を伴う SAH の患者中, 生存が可 能だったのは 4 例 $(6 \%)$ と報告されている の時間が予後と関連するという報告もされている ${ }^{6)}$.

当院での結果で CPA を伴った症例に限定すると, 生存 率は 13 例中 5 例であり, これらの報告と同程度-やや高い 傾向がみられた。

$\mathrm{CPA}$ を伴った SAHの特徴としては, 大半の症例が WFNS Grade Vで搬送されている一方 ${ }^{1)-3) 5)}$, ごく短時間 の CPA では Glasgow Coma Scale(GCS) 8-10 点での搬送 例もあるとされているが, 当院での症例は全例WFNS Grade Vで搬送されていた.

一方, CPAを伴った SAH に対する治療適応について は，心拍再開後に脳神経外科的な加療を受けた例は 0-55\% と，報告によりかなりの差がある(1)315)810)。これらの報告 

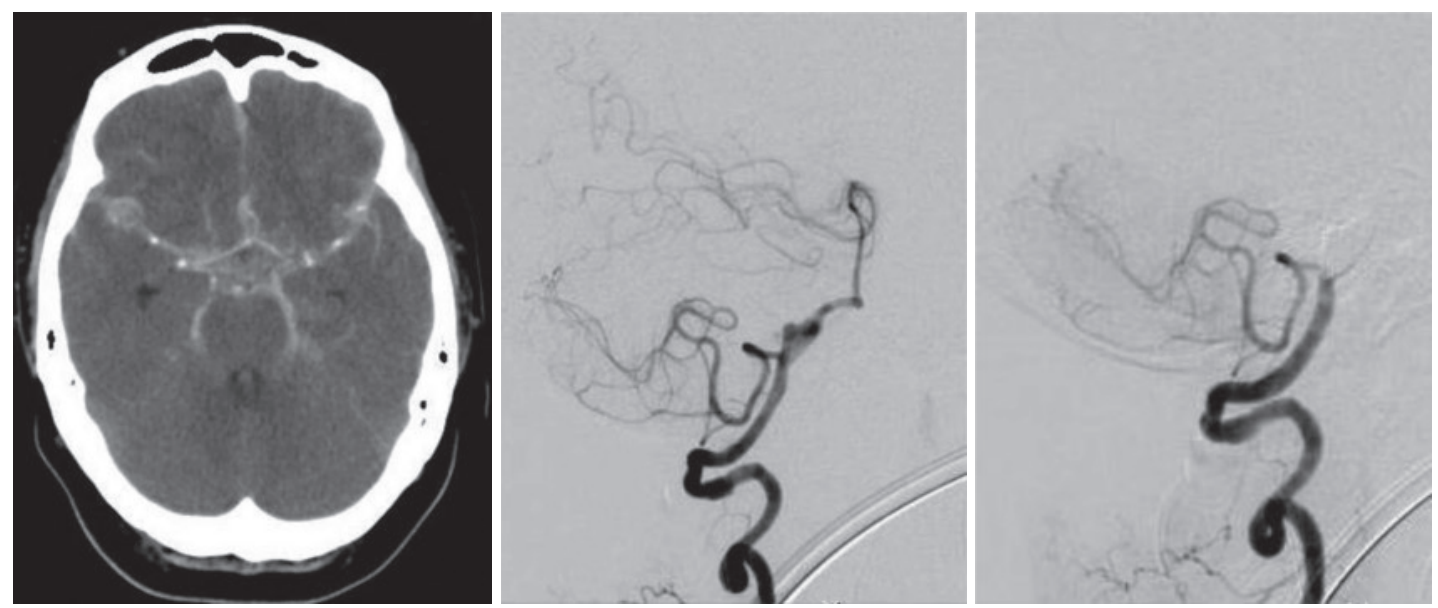

Fig. 3 A 47 year-old woman was admitted to our hospital with loss of consciousness and bilateral dilated pupils. She also had approximately 10 minutes of cardiopulmonary arrest (CPA) in the ambulance. CT scan showed Fisher group 3 subarachnoid hemorrhage (SAH), and digital subtraction angiography (DSA) showed a left vertebral artery dissecting aneurysm. She underwent endovascular internal trapping. Her postoperative course was uneventful and she discharged home with modified Rankin Scale (mRS) 1.

での脳神経外科的加療には脳室ドレナージなどの頭蓋内圧 充進症状に対する加療も含まれており，これをクリッピン グ術やコイル塞栓術といった再破裂予防治療を行った例に 限定すると，積極的に再破裂予防を行っている施設では 50-100\%の例で再破裂予防治療を行っていると報告してい る ${ }^{710)}$. Shapiro ${ }^{7)}$ は 26 例の CPA を伴った SAH 症例のう ち頭蓋内圧コントロールが可能であった 14 例に対して再 破裂予防治療を行っており, 治療 1 力月後の予後良好が $35 \%$ ，vegetative state 拈よび死亡が $65 \%$ と報告してい る。その一方，外科的治療を行わなかった 12 例は全例脳 死状態となったと報告している。

Shapiroの報告から考えると, CPA を伴った SAH 症例 でも再破裂予防治療が施行できれば, 救命率は保存的治療 と比べて高いのは本報告と同椂である。しかし，再破裂予 防治療の適応については各施設の経験や考え方に基づくと ころが多く，一定の基準がないのが現状と思われる．われ われはカテコラミンの非投与下でバイタルサインが安定し ている症例に再破裂予防の治療を行う方針としており，本 基準で再破裂予防の治療を行った症例は大半救命が可能で あったが，その一方で再破裂予防の治療を行わなかった症 例では全例死亡という経過をたどることとなった。しか し, 実際にバイタルサインが安定していない症例でも, 救 命が可能であった症例が存在していた可能性は否定でき ず，適切な治療適応についてはさらなる検討を要すると思 われる。

\section{結論}

重症 SAH，特に再破裂予防の治療にいたるまでに CPA や両側曈孔散大をきたしたような症例では機能的な予後は 不良であるが, カテコラミンの投与なしにバイタルサイン が安定している症例では急性期に積極的な治療を行うこと で救命は可能なことが多く，わずかではあるが予後良好例 も存在する．重症 SAH に対する治療適応についてのさら なる検討と生存例における機能改善に向けた治療方法の開 発が必要であると考えられる。

著者全員は, 日本脳神経外科学会への COI 自己申告を 完了している。本論文に関して，開示すべきCOI はない.

\section{文献}

1) Inamasu J, Nakagawa $Y$, Kuramae $T$, et al: Subarachnoid hemorrhage causing cardiopulmonary arrest: resuscitation profiles and outcomes. Neurol Med Chir (Tokyo) 51: 619-623, 2011

2) Inamasu J, Miyatake S, Tomioka $\mathrm{H}$, et al: Subarachnoid haemorrhage as a cause of out-of-hospital cardiac arrest: a prospective computed tomography study. Resuscitation 80: 977980, 2009

3) Kürkciyan I, Meron G, Sterz F, et al: Spontaneous subarachnoid haemorrhage as a cause of out-of-hospital cardiac arrest. Resuscitation 51: 27-32, 2001

4) Linn FH, Rinkel GJ, Algra A, et al: Incidence of subarachnoid hemorrhage: role of region, year, and rate of computed tomography: a meta-analysis. Stroke 27: 625-629, 1996 
5) Mitsuma W, Ito M, Kodama M, et al: Clinical and cardiac features of patients with subarachnoid haemorrhage presenting with out-of-hospital cardiac arrest. Resuscitation 82: 12941297,2011

6) Miyata K, Mikami T, Asai Y, et al: Subarachnoid hemorrhage after resuscitation from out-of-hospital cardiac arrest. $J$ Stroke Cerebrovasc Dis 23: 446-452, 2014

7) Shapiro S: Management of subarachnoid hemorrhage patients who presented with respiratory arrest resuscitated with bystander CPR. Stroke 27: 1780-1782, 1996

8) Skrifvars MB, Parr MJ: Incidence, predisposing factors, management and survival following cardiac arrest due to subarachnoid haemorrhage: a review of the literature. Scand $J$ Trauma Resusc Emerg Med 20: 75, 2012

9) Skrifvars MB, Varghese B, Parr MJ: Survival and outcome prediction using the Apache III and the out-of-hospital cardiac arrest $(\mathrm{OHCA})$ score in patients treated in the intensive care unit(ICU) following out-of-hospital, in-hospital or ICU cardiac arrest. Resuscitation 83: 728-733, 2012

10) Toussaint LG 3rd, Friedman JA, Wijdicks EF, et al: Survival of cardiac arrest after aneurysmal subarachnoid hemorrhage. Neurosurgery 57: 25-31, 2005

11) Vergouwen MD, Fang J, Casaubon LK, et al: Higher incidence of in-hospital complications in patients with clipped versus coiled ruptured intracranial aneurysms. Stroke 42: 3093-3098, 2011

12) Wartenberg KE, Schmidt JM, Claassen J, et al: Impact of medical complications on outcome after subarachnoid hemorrhage. Crit Care Med 34: 617-623, 2006 